\title{
The Development of an Online Surveillance of Digital Media Use in Early Childhood Question- naire-SMALLQTM- For Singapore
}

\author{
Michael Yong Hwa Chia ${ }^{1}$, Lee Yong Tay², Terence Buan Kiong Chua ${ }^{1}$
}

\begin{abstract}
Affiliations: 'National Institute of Education, Nanyang Technological University, Physical Education and Sports Science Academic Group, Singapore, ${ }^{2}$ National Institute of Education, Nanyang Technological University, Office of Education Research, Singapore
\end{abstract}

Correspondence: M.Y.H. Chia, National Institute of Education, Nanyang Technological University, Physical Education and Sport Science, 1 Nanyang Walk, Singapore 637616, E-mail: michael.chia@nie.edu.sg

ABSTRACT Digital media engagement in families in Singaporean society is increasing at an unprecedented pace. Limited research in the last five years in Singapore shows that young children experience significant amounts of screen time from television, computers and other forms of mobile digital devices, even before primary school. For children, digital media use can aid with learning, but its overuse has inimical effects on learning and health. As digital media use in children increases faster than research on its impact, it is essential to develop a tool that can monitor changes in digital media habits of children over time. This study aimed to develop an online questionnaire for parents to report on the digital media habits of children. An online questionnaire bundle, Surveillance of digital-Media hAbits in earLy chiLdhood Questionnaire (SMALLQ ${ }^{\mathrm{m}}$ ), organized into sections ((I) Digital-media use of parent and child, (II) Non-digital media behaviour of the child, (III) Parent and child information) was developed for the purpose of charting digital media use and changes over three years $\left(2018,2019\right.$, and 2020). The results showed that SMALLQ ${ }^{\mathrm{ma}}$ has face and content validity and was practicable for Singapore. Furthermore, based upon a similar methodology for developing the SMALLQ ${ }^{m}$, the development of Child-SMALQ (Surveillance of digital MediA use in chiLdhood questionnaire) and Adolescent-SMALQ (Surveillance of digital MediA use in adoLescence questionnaire) are directions for future research.

KEY WORDS surveillance, development, questionnaire, SMALLQ ${ }^{\text {in }}$

$@ M J S S M o n t e n e g r o$

DEVELOPMENT OF ONLINE SMALLQ

$\mathrm{http}: / / \mathrm{mjssm} \cdot \mathrm{me} /$ ?sekcija= article\&artid=185

\section{Introduction}

Research shows that people of all ages in developed and developing countries use digital media significantly on a daily basis because of the high penetration rate of the internet, work and school culture, societal environment and the ubiquity of mobile technologies (American Academy of Pediatrics (AAP), 2011; Canadian Paediatric Society (CPS), 2017). Some scholars suggest that young children's interacting with digital media can help with learning and literacy (AAP, 2016). Other scholars opine that an early adoption of these digital media socializes young people to sedentary lifestyles, leading to obesity, an earlier onset of type II diabetes, technology addiction, displacement of other meaningful activities, such as real-time parent-child interaction, physical play and physical activity, impaired self-regulation, and delayed expressive speech, among other insidious outcomes (CPS, 2017). International organizations, such as UNESCO Bangkok (2015), advocate maximizing children's digital opportunities in an attempt to ameliorate the digital divide with caution and concern for the inimical consequences. Some health ailments have their genesis in childhood, and it is crucial to curb their entrenchment as early as possible. Digital devices (fixed screens (television, desktop computers) and mobile screens (smartphones, tablets)) originally targeted at adults are now increasingly available to preschool children, with or without parental supervision. Research into the effects of such digital media exposure

Received: January 082019 | Accepted after revision: March 242019 | First published online: September 012019

(C) 2019 by the author(s). License MSA, Podgorica, Montenegro. This article is an open access article distributed under the terms and conditions of the Creative Commons Attribution (CC BY).

Conflict of interest: None declared. 
on the health and development of preschool children in the context of urban areas in Asia cannot match the increased use of such parent-owned technologies. As digital media use among young people changes rapidly over time and increases with age (AAP, 2011; Bernard et al., 2017), there is a need for a common measurement tool, such as the SMALLQ ${ }^{\mathrm{m}}$, to chart and monitor children's digital media use over different critical periods, for example, in school transitions (preschool to primary and to secondary school) as transitions from early childhood, childhood, and adolescence.

\section{Method}

\section{Ethical clearance}

Prior to the research, the authors obtained ethics clearance from the Nanyang Technological University - Institutional Review Board (IRB-2017-09-036).

\section{Development and face validity of the SMALLQ ${ }^{\text {TM }}$}

The questionnaire was developed in Singapore using the AMEE framework- Guide No.87 (Artino, Rochelle, Dezee, \& Gehlbach, 2014). The seven-step framework is used to develop high-quality surveys that are suitable for programme evaluation and research. The seven steps include (1) literature review, (2) focus group interviews, (3) synthesis of the literature review and focus group outcomes, (4) development, modification or re-order of the questionnaire items, (5) feedback on the items through expert opinion, (6) employment of cognitive interviews to ensure that respondents understand the items as intended, and (7) pilot testing the online questionnaire. A unique feature of this process is that it blends the views of potential participants and that of experts, thereby front-loading the validity of responses via careful item selection (Artino et al., 2014).

A thorough review of media use questionnaires reported on children was made, and initial drafts of the questionnaire were produced. Some of these included items in the "Zero-to-eight Children's Media Use in America" (CommonSense, 2011) as well as the "Early Years Physical Activity Questionnaire" (Bingham et al., 2016). Initial draft questionnaire items numbered about 40 (a juxtaposition of media use and physical activity) and focused mainly on soliciting parent's response to the type of devices used to access digital media in general and did not differentiate between weekday and weekend use. Focus group discussions were conducted between the researchers and several experts in questionnaire design, early childhood specialists and stakeholders in education to gauge the relevance and appropriateness of questionnaire items. Specifically, for the development of the online SMALLQ ${ }^{\mathrm{m}}$ in Singapore, the group included an early childhood expert, an advisor to early childhood government agency, a senior lecturer in early childhood and an associate professor who lectures in graduate courses on questionnaire development and design, a pedagogy specialist working in preschool, and five parents of children attending preschools in Singapore. They independently reviewed early versions of the questionnaire and guided the development of new questions that were contextually relevant, of concern and interest, and useful for tracking over time for Singapore. A specialist for the Qualtrics platform provided technical expertise on the functionalities, security and confidentiality of using the online platform. This eventually led to the formulation of a new online survey entitled "Surveillance of digital Media hAbits in earLy chiLdhood Questionnaire", aptly encapsulated in the acronym "SMALLQ", for which a trademark application (TM120494 Class 41 under education research) was made in Singapore, in 2018. Cognitive load and the ease of understanding of the questionnaire items were tested with the focus group, and, where necessary, the questionnaire items were refined and reorganized before the final 25-item SMALLQ ${ }^{\text {tw }}$ was accomplished and hosted online on the Qualtrics platform. Leadership teams and principals from the preschools, and parents of preschool children outside of this study participated in a feasibility study. Feedback on the usability of SMALLQ ${ }^{\mathrm{T} x}$ on mobile devices was solicited, and the researchers further refined the interface to improve the end-user experience (i.e., parents answering the online SMALLQ ${ }^{\mathrm{m}}$ ). Four independent experts who were not involved in the research established the face validity of the SMALLQ $^{\mathrm{m}}$.

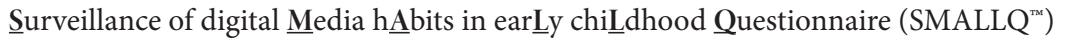

The online SMALLQ ${ }^{\mathrm{T} \omega}$ sought information in three segments: (i) digital media use, parent benefit, concern, knowledge and practice of guidelines, outside of school on weekday and weekend; (ii) non-digital media habits: indoor and outdoor play, day time naps, non-screen reading, and drawing; (iii) parent educational attainment and household income, additional child information: height, weight, wearing spectacles or not, and night-time sleep. Specifically, the SMALLQ ${ }^{\mathrm{m}}$ instructed respondents to provide information about:

\section{Digital media environment at home}

Parents were asked about the type of technological devices that children had access to outside of school (e.g., at home). These included fixed screens such as television, desktop computers and game consoles, mobile screens such as smartphones, tablets and other hand-held devices and technological toys.

\section{Parent digital media habits}

Parents were queried about their digital habits on a typical weekday and on a typical weekend day. The choices were segregated as use for work, entertainment, social networking and for personal development. 
Digital media habits of the child outside of pre-school/ kindergarten

Parents were asked to provide details of children's digital media habits outside of pre-school/ kindergarten, on a typical weekday, and on a typical weekend day. This included the frequency, duration and purpose of digital media use (for learning, for entertainment, for communication) on fixed screens and on mobile screens.

\section{Parent perception of digital media use}

Parents were asked to indicate their perceived importance of digital media use to them and to their child using a 5-point Likert scale from "not important" to "very important". Options for the benefit to the child include "Improve knowledge and skills", "Entertainment", and "Communication". Options for the benefit to parent include "Keep child occupied", "Distract or divert the attention of the child" and "Put the child to sleep".

\section{Parent concern of child digital media use}

Parents reported their perceived concerns about digital media usage by their child on a 5-point Likert scale from "not concerned" to "seriously concerned". Options for parents include "Poor sleep", "Poor eyesight", "Lack of physical exercise or play", "Exposure to inappropriate content", "Addiction”, and "Lack of parent-child interaction".

Parent awareness and practice of guidelines on digital media use by children

Parents were asked to indicate whether they are aware of the four professional guidelines on digital media use by children and if they practised those guidelines. The guidelines are (i) Limit digital media use for children younger than two years, (ii) Limit screen time to 1 hour per day for children 2-5 years, (iii) Introduce only high-quality educational programmes for children 18-24 months, and (iv) Co-watch or co-play digital media with a children.

\section{Non-digital habits of the child outside of pre-school/ kindergarten}

Parents were also asked to report about their child's physical activity and play on a typical weekday and weekend day outside of the preschool. This included the duration spent on various indoor activities (non-screen reading and drawing), indoor play and outdoor play, and an estimated apportion of time their child spent on moderate-to-vigorous activities, which caused their child to breathe harder and faster.

\section{Demographic information}

The SMALLQ ${ }^{\mathrm{s}}$ also included demographic questions about the participants (e.g., relationship to the child, monthly household income, highest educational attainment, race) and their child (e.g., gender, age, height and weight, whether the child wore spectacles or not, sleep duration, and sleep quality).

A sample of SMALLQ ${ }^{\mathrm{mw}}$ and acknowledgement of help is shown in Annex 1.

\section{Results}

In testing the online SMALLQ ${ }^{\mathrm{m}}$, we received 137 completed surveys from teachers, parents, and school leaders of preschool centres and kindergartens in Singapore. These participants were not part of a more extensive three-year tracking study, which, commenced in 2018 and will end in 2020. The average time taken to complete the online survey in a single sitting was between 20 and 30 minutes; $66 \%$ of respondents used the QR code to access the SMALLQ ${ }^{\text {tw }}$ while $34 \%$ used the anonymous internet-link. In terms of qualitative online feedback from respondents, the use of "drop-down options" for choices was preferred to the use of "slider-scales". These were noted, and amendments were made to the SMALLQ ${ }^{\mathrm{ma}}$ to enhance its utility and ease of response for participants of the survey. Overall, the qualitative comments from respondents in the pilot test were affirmative. There was agreement and concurrence among the qualitative comments of the four independent experts who commented on the SMALLQ ${ }^{\mathrm{mx}}$ and established its face and content validity.

\section{Discussion}

The purpose of the pilot research was to develop an online questionnaire that holistically examines the digital media use of preschool children aged between two and six years old, indoor and outdoor play, parents digital media habits, their concerns, awareness of digital media use guidelines and their enforcement, and socioeconomic background of parents. The development of the SMALLQ ${ }^{\mathrm{m}}$ adhered to the seven-step process described by Artino et al. (2014). The results showed that parents, teachers and school leaders who were not involved in the main study took between 20-30 minutes to complete the online SMALLQ ${ }^{\mathrm{Tm}}$ in a single sitting, albeit, many did so in more than one sitting. The response rate was higher when participants completed the online SMALLQ ${ }^{\mathrm{m}}$ as a group such as during a briefing session about the research. However, such an arrangement may not be feasible for the actual launch of the research since opportunities where parents of preschool children congregate as a group are infrequent. However, there is an advantage to the questionnaire being online since the reach to parents of children who enrolled in the preschools is greater. Feedback from users about the improving upon the functionality of the online survey such as the use of "drop-down" options instead of "slider-scales" and the merits of using both QR codes and anonymous internet-link to access the SMALLQ ${ }^{\text {max }}$, was accommodated. 
In conclusion, the SMALLQ ${ }^{\mathrm{m}}$ was adjudged to have acceptable face validity, was relevant and appropriate for use as monitoring tool of digital media use in early childhood and has the potential to be adapted for use in childhood as Child-SMALQ (surveillance of digital media use in childhood questionnaire) and in adolescence as Adolescent-SMALQ (surveillance of digital media use in adolescence questionnaire). These online questionnaires can be translated into other languages for international comparisons of digital media use among participants from early childhood, childhood, and adolescence.

\section{Acknowledgement}

We express our thanks and appreciation to experts from the National Institute of Education, Nanyang Technological University, Early Childhood Development Agency, and the Ministry of Education Preschool Education Branch in Singapore for their insightful inputs to earlier drafts of the questionnaire. We are grateful to parents, principals, teachers of the four-anchor operator of preschools for their inputs in the focus group discussions. Their generous sharing was invaluable to the development of the Surveillance of digital MediA use in earLy chiLd-hood.Questionnaire-SMALLQ..

\section{REFERENCES}

American Academy of Pediatrics. (2011). Policy statement: Children, adolescents, obesity, and the media. Pediatrics, 128(1), 201-208.

American Academy of Pediatrics. (2016). Media and young minds. Pediatrics, 138(5), e20162591. doi: 10.1542/ peds.2016-2591

Artino, A. R., Rochelle, J. S., Dezee, K. J., \& Gehlbach, H. (2014). Developing questionnaires for educational research: AMEE Guide No. 87. Medical Teacher, 36(6), 463-474. doi:10.3109/0142159x.2014.889814

Bernard, J. Y., Padmapriya, N., Chen, B., Cai, S., Tan, K. H., Yap, F., ... \& Kramer, M. S. (2017). Predictors of screen viewing time in young Singaporean children: the GUSTO cohort. International Journal of Behavioral Nutrition and Physical Activity, 14(1), 112. doi: 10.1186/s12966-017-0562-3

Bingham, D. D., Collings, P. J., Clemes, S. A., Costa, S., Santorelli, G., Griffiths, P., \& Barber, S. E. (2016). Reliability and validity of the early years physical activity questionnaire (EY-PAQ). Sports, 4(2), 30. doi: $10.3390 /$ sports 4020030

Canadian Paediatric Society. (2017). Screen time and young children: Promoting health and development in a digital world. Paediatrics \& Child Health, 22(8), 461-468. doi: 10.1093/pch/pxx123

CommonSense Research Study (2011). Zero to Eight: Children's Media Use in America. Retrieved from https:// www.commonsensemedia.org/research/zero-to-eight-childrens-media-use-in-america

SMALLQ ${ }^{\text {mix }}$ - Surveillance of digital MediA use in earLy chiLdhood Questionnaire, trademarked under TM120494 Class 41 in Singapore in 2018.

UNESCO Bangkok (2015). Fostering digital citizenship through safe and responsible use of ICT. Asia and Pacific Regional Bureau for Education. Retrieved from https://bangkok.unesco.org/content/safe-effective-and-responsible-use-ict 